\title{
ARTICLE \\ Osthole prevents tamoxifen-induced liver injury in mice
}

\author{
Wen-bo Zhou ${ }^{1}$, Xin-xin Zhang ${ }^{1}$, Yun Cai ${ }^{1}$, Wu Sun ${ }^{1}$ and Hao $\mathrm{Li}^{1}$
}

Tamoxifen (TMX) is an antiestrogen drug that is used in the treatment and prevention of all stages of estrogen-dependent breast cancer. Adverse effects of TMX include hepatotoxicity. In this study, we investigated the therapeutic effects of osthole, isolated from medicinal plants especially Fructus Cnidii, on TMX-induced acute liver injury in mice. Mice were injected with osthole (100 mg/kg, ip) or vehicle, followed by TMX ( $90 \mathrm{mg} / \mathrm{kg}$, ip) $24 \mathrm{~h}$ later. We showed that a single injection of TMX-induced liver injury and oxidative stress. Pretreatment with osthole attenuated TMX-induced liver injury evidenced by dose-dependent reduction of serum alanine aminotransferase (ALT) and aspartate aminotransferase (AST) activities. Pretreatment with osthole also blunted TMX-induced oxidative stress, evidenced by significant increase of reduced glutathione (GSH) as well as reduction of malondialdehyde (MDA) and hydrogen peroxide $\left(\mathrm{H}_{2} \mathrm{O}_{2}\right)$. Consistently, osthole significantly enhanced the expressions of antioxidant genes (GPX1, SOD2, GCL-C, and G6pdh), but suppressed those of pro-oxidant genes (NOX2 and ACOX). Furthermore, osthole inhibited the production of inflammatory cytokines, reduced the metabolic activation of TMX, and promoted its clearance. We further revealed that osthole elevated hepatic CAMP and cGMP levels, but inhibition of PKA or PKG failed to abolish the hepatoprotective effect of osthole. Meanwhile, prominent phosphorylation of p38 was observed in liver in response to TMX, which was significantly inhibited by osthole. Pretreatment with SB203580, a p38 inhibitor, significantly attenuated TMX-induced increase of ALT and AST activities, reduced oxidative stress, and reversed the alterations of gene expression caused by TMX. Moreover, pretreatment with L-buthionine sulfoximine (BSO), an inhibitor of GSH synthesis, partly reversed the effect of osthole on TMX-induced liver injury. Consistently, pretreatment with N-acetyl-L-cysteine (NAC) significantly attenuated TMX-induced increase in ALT and AST activities. Notably, both BSO and NAC had no detectable effect on the phosphorylation levels of p38. Collectively, our results suggest that osthole prevents TMX hepatotoxicity by suppressing p38 activation and subsequently reducing TMX-induced oxidative damage.

Keywords: hepatotoxicity; tamoxifen; oxidative stress; osthole; MAPK; SB203580; L-buthionine sulfoximine; N-acetyl-L-cysteine

Acta Pharmacologica Sinica (2019) 40:608-619; https://doi.org/10.1038/s41401-018-0171-y

\section{INTRODUCTION}

Tamoxifen (TMX), 1-[4-(2-dimethyl-aminoethoxy) phenyl]-1,2diphenyl-1-butene), is a nonsteroidal antiestrogen drug that is used to treat and prevent all stages of estrogen-dependent breast cancer [1]. An adjuvant TMX treatment increases recurrence-free survival and overall survival in patients with hormone receptorpositive breast tumors, regardless of their nodal status, menopausal status, or age [2]. With the widespread therapeutic and emerging prophylactic use of TMX, side effects of the drug, particularly its organ-specific toxicity, have been extensively discussed. Cases of TMX-induced hepatotoxicity have been described, including toxic hepatitis, massive hepatic steatosis, multifocal hepatic fatty infiltration, submassive hepatic necrosis, and even cirrhosis in humans [2].

The hepatotoxicity of TMX has been attributed to impaired mitochondrial $\beta$-oxidation of fatty acids and the generation of reactive oxygen species (ROS) [3-5]. TMX exerts multiple deleterious effects on the mitochondria, including reducing the phosphorylation efficiency, compromising the electron transfer along the electron transport chain, and affecting mitochondrial membrane integrity [6]. These effects lead to mitochondrial dysfunction and a subsequent increase in ROS production. Additionally, metabolic activation of TMX also contributes to the overproduction of ROS. TMX is actually a prodrug that exerts its therapeutic effects after it has been transformed in the liver by cytochrome P450 (CYP) enzymes [7]. ROS are produced simultaneously during this process. TMX is detoxified via phase II conjugation to nontoxic glucuronide metabolites [8].

Osthole (also known as osthol), 7-methoxy-8-(3-methyl-2-butenyl)$2 \mathrm{H}$-1-benzopyran-2-one, is a natural coumarin that was first isolated from the Cnidium plant. High contents of osthole are present in the mature fruit of Cnidium monnieri (Fructus Cnidii), which is commonly applied in the clinical practice of traditional Chinese medicine $[9,10]$. Osthole is also present in a wide range of other medicinal plants, including Angelica, Archangelica, citrus, and Clausena. Osthole has multiple functions, including anti-inflammatory, antitumor, antiapoptosis, antithrombosis, and antiaggregation activities [11]. The hepatoprotective effect of osthole has been reported in several studies. Osthole has been reported to suppress the secretion of hepatitis $B$ virus (HBV) in cell culture and prevent hepatitis in mice induced by concanavalin A or an anti-Fas antibody [12-14]. Osthole exerts therapeutic effects on both hyperlipidemic [15] and alcoholic fatty liver [16], ameliorates hepatic fibrosis, inhibits hepatic stellate cell activation [14], promotes antitumor immune responses [16-18], and inhibits the growth of hepatocellular carcinoma [19]. Osthole

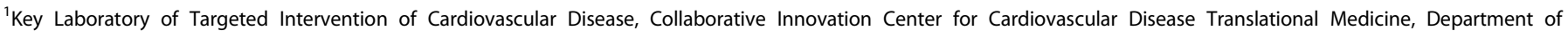
Pathophysiology, Nanjing Medical University, Nanjing 211166, China

Correspondence: Hao Li (haoli@njmu.edu.cn)

Received: 17 April 2018 Accepted: 14 September 2018

Published online: 12 October 2018 
Osthole prevents tamoxifen-induced liver injury in mice WB Zhou et al.

also protects against liver damage in a rodent model of traumainduced hemorrhaging [20]. As shown in our recent study, osthole is an effective treatment for acetaminophen (APAP)-induced liver injury [21], a process that is mainly caused by overwhelming oxidative stress [22]. However, the effect of osthole on TMX-induced hepatotoxicity has not been assessed. In the present study, we examined the effect of osthole on TMX-induced acute liver injury and investigated the underlying mechanism.

\section{MATERIALS AND METHODS}

Animal husbandry and drug treatment

Seven-week-old male BALB/C mice used in this study were purchased from the experimental animal center of Nanjing Medical University (Nanjing, China). Mice were allowed free access to drinking water and food, and were housed at room temperature $\left(25^{\circ} \mathrm{C}\right)$ with an automatic 12-h light and 12-h dark cycle. Osthole (purity >98\%) was purchased from MedChem Express (Shanghai, China). Osthole was dissolved in a 1:9 ( $/ / \mathrm{v})$ mixture of Tween 80 and $0.9 \%$ sodium chloride and administered intraperitoneally at the indicated doses (100 mg/kg in most cases). After $24 \mathrm{~h}$, mice were intraperitoneally injected with a single injection of TMX (Sigma, St Louis, USA, $90 \mathrm{mg} / \mathrm{kg}$ ) dissolved in saline. Mice were anesthetized with $60 \mathrm{mg}$ of sodium pentobarbi$\mathrm{tal} / \mathrm{kg}$ body weight via an intraperitoneal injection at various time points after the TMX or control injection. Serum was collected and livers were harvested for further assays. In some experiments, after pretreatment with osthole $(100 \mathrm{mg} / \mathrm{kg}), \mathrm{H} 89$ (N-[2-(p-bromocinnamylamino)ethyl]-5-isoquinolinesulfonamide dihydrochloride; Sigma, USA, $10 \mathrm{mg} / \mathrm{kg}$ ), KT5823 (Sigma, USA, $25 \mathrm{mg} / \mathrm{kg}$ ), or Lbuthionine sulfoximine (BSO, Sigma, USA, $1 \mathrm{~g} / \mathrm{kg}$ ) was administered intraperitoneally $1 \mathrm{~h}$ prior to TMX. In certain experiments, mice were injected with SB203580 (4-(4-fluorophenyl)-2-(4methylsulfinylphenyl)-5-(4-pyridyl)-1H-imidazole; Sigma, USA, 2 $\mathrm{mg} / \mathrm{kg}$ ) or N-acetyl-L-cysteine (NAC, Sigma, USA, $150 \mathrm{mg} / \mathrm{kg}$ ) instead of osthole $1 \mathrm{~h}$ before the injection of TMX. All animal protocols were pre-approved by the Animal Care and Use Committee of Nanjing Medical University.

Chemical assays of serum and liver parameters

Enzymatic activities of alanine aminotransferase (ALT) and aspartate aminotransferase (AST) in serum were estimated spectrophotometrically using commercially available kits (Jiancheng Bioengineering, Nanjing, China). Serum malondialdehyde (MDA) levels were measured using a colorimetric assay according to the manufacturer's instructions (Jiancheng Bioengineering, Nanjing, China). Frozen liver tissues were thawed and homogenized in ice-cold PBS (phosphate-buffered saline) to determine the contents of hydrogen peroxide $\left(\mathrm{H}_{2} \mathrm{O}_{2}\right)$, reduced glutathione (GSH), and lipid peroxide (LPO). The homogenate was centrifuged at $900 \times g$ for $10 \mathrm{~min}$ at $4{ }^{\circ} \mathrm{C}$, and the supernatants were collected. Levels of $\mathrm{H}_{2} \mathrm{O}_{2}, \mathrm{GSH}$, and LPO were determined using commercially available assay kits according to the manufacturer's instructions (Jiancheng Bioengineering, Nanjing, China).

Measurement of CAMP and cGMP concentrations

The concentrations of cAMP and cGMP were determined using commercially available enzyme immunoassay kits (Elabscience, Wuhan, China). Frozen liver tissues were thawed and homogenized in ice-cold PBS. After centrifugation at $900 \times g$ for 10 min at $4{ }^{\circ} \mathrm{C}$, the supernatants were analyzed for CAMP and cGMP levels according to the manufacturer's instructions.

Histopathology

Liver tissues were fixed with $10 \%$ formalin and embedded in paraffin for histological assessments. Samples were subsequently sectioned $(5 \mu \mathrm{m})$, stained with hematoxylin and eosin (H\&E) and examined under a microscope (Olympus, Japan).
Table 1. Primers used to detect gene expression at mRNA level

\begin{tabular}{|c|c|}
\hline Gene name & Primer sequences $\left(5^{\prime}-3^{\prime}\right)$ \\
\hline \multirow[t]{2}{*}{ GPX1 } & F: CCAGGAGAATGGCAAGAATGA \\
\hline & R: TCTCACCATTCACTTCGCACTT \\
\hline \multirow[t]{2}{*}{ SOD2 } & F: TCCCAGACCTGCCTTACGACTAT \\
\hline & R: GGTGGCGTTGAGATTGTTCA \\
\hline \multirow[t]{2}{*}{ GCL-c } & F: GTTATGGCTTTGAGTGCTGCAT \\
\hline & R: ATCACTCCCCAGCGACAATC \\
\hline \multirow[t]{2}{*}{ G6pdh } & F: CTGGAACCGCATCATCGTGGAG \\
\hline & R: CCTGATGATCCCAAATTCATCAAAATAG \\
\hline \multirow[t]{2}{*}{ NOX2 } & F: GAAAACTCCTTGGGTCAGCACT \\
\hline & R: ATTTCGACACACTGGCAGCA \\
\hline \multirow[t]{2}{*}{ ACOX } & F: TCGAAGCCAGCGTTACGAG \\
\hline & R: GGTCTGCGATGCCAAATTCC \\
\hline \multirow[t]{2}{*}{ CYP3A11 } & F: ACCACCAGTAGCACACTTTC \\
\hline & R: CCAGGTATTCCATCTCCATCAC \\
\hline \multirow[t]{2}{*}{ CYP2E1 } & F: TGTGACTTTGGCCGACCTGTTC \\
\hline & R: CAACACACACGCGCTTTCCTGC \\
\hline \multirow[t]{2}{*}{ CYP2D6 } & F: CCGCCTTCGCTGACCATAC \\
\hline & R: CGATCACGTTACACACTGCTT \\
\hline \multirow[t]{2}{*}{ CYP4A10 } & F: CAACTTGCCCATGATCACACA \\
\hline & R: CATCCTGCAGCTGATCCTTTC \\
\hline \multirow[t]{2}{*}{ UGT1A1 } & F: CACCTGAAGCCTCAATACACAT \\
\hline & R: CAGTCCGTCCAAGTTCCACC \\
\hline \multirow[t]{2}{*}{ UGT1A6 } & F: GTTTCTCTTCCTAGTGCTTTGGG \\
\hline & R: CCTCGTTCACTGAGATGTTCTAC \\
\hline \multirow[t]{2}{*}{ UGT2B1 } & F: GTGCTGGTGTGGCCTACAG \\
\hline & R: CAGAAGATATGAGAACGGTGACG \\
\hline \multirow[t]{2}{*}{ SULT2A1 } & F: CCATCTTCCCATCCATCTCTTC \\
\hline & R: GAGTGACCCTGGATTCTTCAC \\
\hline \multirow[t]{2}{*}{ GSTM } & F: ATACTGGGATACTGGAACGTCC \\
\hline & R: AGTCAGGGTTGTAACAGAGCAT \\
\hline \multirow[t]{2}{*}{ IL-6 } & F: CTGCAAGAGACTTCCATCCAG \\
\hline & R: AGTGGTATAGACAGGTCTGTTGG \\
\hline \multirow[t]{2}{*}{ IL-1 $\beta$} & F: TTCAGGCAGGCAGTATCACTC \\
\hline & R: GAAGGTCCACGGGAAAGACAC \\
\hline \multirow[t]{2}{*}{ MCP-1 } & F: ACTGAAGCCAGCTCTCTCTTCCTC \\
\hline & R: TTCCTTCTTGGGGTCAGCACAGAC \\
\hline \multirow[t]{2}{*}{ CXCL10 } & F: CCAAGTGCTGCCGTCATTTTC \\
\hline & R: GGCTCGCAGGGATGATTTCAA \\
\hline \multirow[t]{2}{*}{ TNF $\alpha$} & F: CCAGGCGGTGCCTATGTCTC \\
\hline & R: CAGCCACTCCAGCTGCTCCT \\
\hline \multirow[t]{2}{*}{ GAPDH } & F: AGGTCGGTGTGAACGGATTTG \\
\hline & R: GGGGTCGTTGATGGCAACA \\
\hline
\end{tabular}

Dihydroethidium (DHE) staining

After harvest, liver tissues were immediately embedded in optimum cutting temperature (OCT) compound and frozen in liquid nitrogen. Frozen tissue blocks were subsequently sectioned $(5 \mu \mathrm{m})$, stained with DHE $(10 \mu \mathrm{mol} / \mathrm{L}$; Beyotime, Shanghai China) for $20 \mathrm{~min}$ at $37^{\circ} \mathrm{C}$, and examined under a fluorescence microscope (Olympus, Japan).

Western blotting

Liver tissues $(100 \mathrm{mg})$ were homogenized and lysed with RIPA (radioimmunoprecipitation assay) buffer containing protease inhibitors (Roche Diagnostics, Switzerland) for $15 \mathrm{~min}$ on ice. After centrifugation at $20,000 \times g$ for $15 \mathrm{~min}\left(4^{\circ} \mathrm{C}\right)$, the protein concentrations in the samples were determined using the Bradford method. Proteins ( $50 \mu \mathrm{g}$ per lane) were loaded onto SDS-polyacrylamide gels 

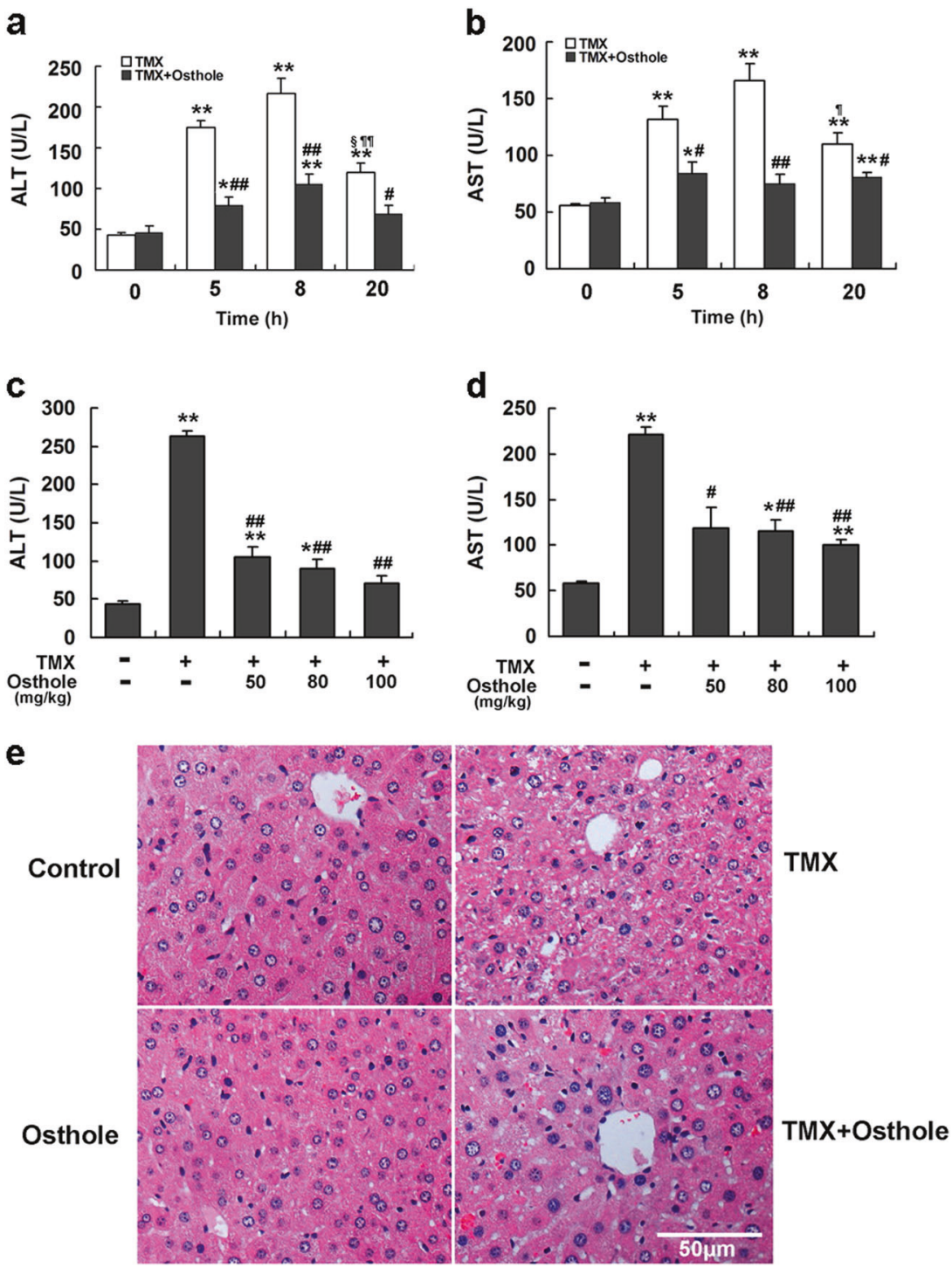

Fig. 1 Osthole reduced TMX-induced liver injury. a, b Mice were intraperitoneally injected with osthole (100 mg/kg). After $24 \mathrm{~h}$, TMX ( $90 \mathrm{mg} /$ $\mathrm{kg}$ ) was administered to mice. Mice were sacrificed at the indicated times after the TMX injection. Serum ALT and AST activities were determined. Data are reported as the mean \pm SEM, $n=4-5$ mice per group. ${ }^{*} P<0.05,{ }^{*} P<0.01$ compared to $0 \mathrm{~h}$, ${ }^{\#} P<0.05$, \#\# $P<0.01$ compared to TMX, ${ }^{\S} P<0.05$ compared to $5 \mathrm{~h}$, ${ }^{~}{ }^{19} P<0.01$ compared to $8 \mathrm{~h}$. $\mathbf{c}$, d Dose-dependent responses of serum ALT and AST activities in mice to osthole $8 \mathrm{~h}$ after the TMX treatment. Data are presented as the mean \pm SEM, $n=4-5$ mice per group. ${ }^{*} P<0.05, * * P<0.01$ compared to the control, ${ }^{\#} P<0.05,{ }^{\# \#} P<0.01$ compared to TMX. e Representative images of H\&E-stained liver sections ( $\times 100$ magnification)

and blotted onto methanol-activated PVDF membranes. PhosphoErk (Thr202/Tyr204, \#9101), Erk (\#9102), phospho-p38 (Thr180/ Tyr182, \#9211), p38 (\#9212), phospho-JNK (Thr183/Tyr185, \#9251), and JNK (\#9252) antibodies were obtained from Cell Signaling Technology. Glyceraldehyde-3-phosphate dehydrogenase (GAPDH) (\#G8795, Sigma) was used as an internal control. Enhanced chemiluminescence was used to detect the signals according to the manufacturer's instructions (Amersham Biosciences, Boston, USA).

Quantitative real-time PCR

Total cellular RNA was extracted using Trizol reagent (Takara, Japan) according to the manufacturer's instructions. The total RNA $(2 \mu \mathrm{g})$ was reverse transcribed using a PrimeScript RT Reagent Kit (Takara, Japan). Real-time PCR was performed with Power SYBR Green PCR Master Mix (Applied Biosystems) using an Applied Biosystems 7500 Real-Time PCR System. The primer sequences are listed in Table 1. The relative quantities of each mRNA were determined using the comparative cycle threshold method and normalized to the GAPDH mRNA.

Statistical analysis

Data are presented as the mean \pm SEM. Statistical significance was assessed using one-way analysis of variance and Scheffe's test. In all statistical comparisons, a $P$ value $<0.05$ was used to indicate a statistically significant difference.

\section{RESULTS}

Osthole prevented TMX-induced liver injury

Several dosages of TMX was injected into mice to generate an acute model of TMX-induced liver injury (Supplementary Figure S1). Compared with the control, a single intraperitoneal injection of $90 \mathrm{mg} / \mathrm{kg}$ TMX significantly increased serum ALT and AST 
a

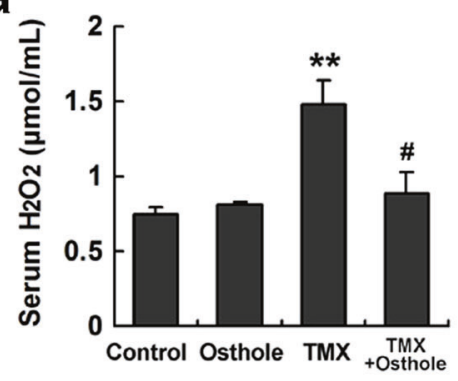

C

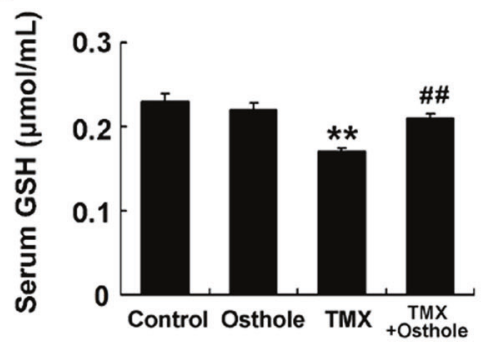

e

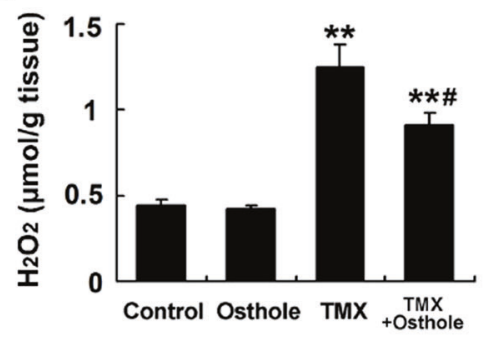

g

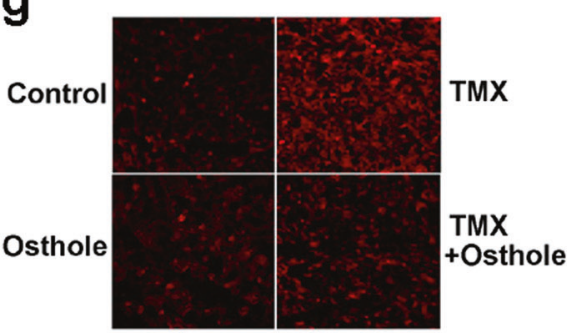

b

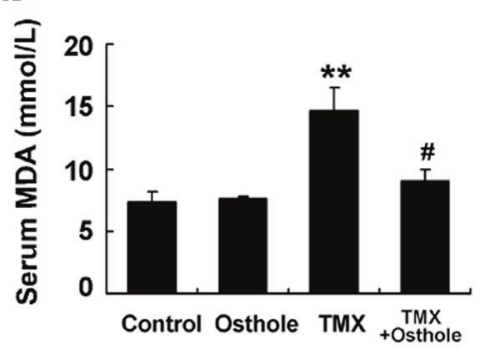

d

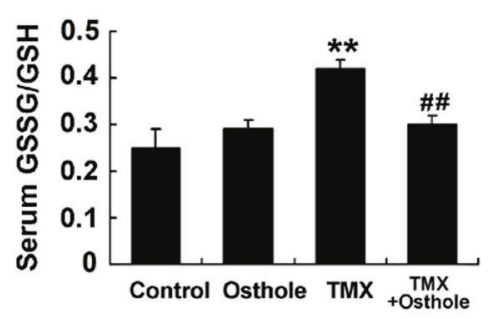

f
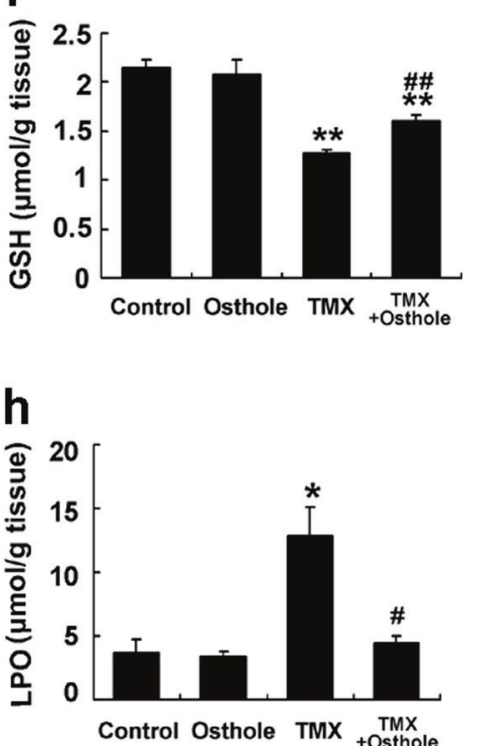

Fig. 2 Osthole reduced TMX-induced oxidative stress. Mice were intraperitoneally injected with osthole (100 mg/kg). After $24 \mathrm{~h}$, TMX ( $90 \mathrm{mg} /$ $\mathrm{kg}$ ) was administered to mice. Mice were sacrificed $8 \mathrm{~h}$ after the TMX injection. Serum $\mathrm{H}_{2} \mathrm{O}_{2}(\mathbf{a}), \mathrm{MDA}$ (b), and GSH levels (c) and the GSSG-toGSH ratio (d) were determined. Hepatic levels of $\mathrm{H}_{2} \mathrm{O}_{2}(\mathbf{e}), \mathrm{GSH}(\mathbf{f})$, ROS (detected using DHE staining) (g), and lipid peroxides (h) were examined. Data are presented as the mean \pm SEM, $n=4-5$ mice per group. ${ }^{* *} P<0.01$ compared to the control, ${ }^{\#} P<0.05$, ${ }^{\# \#} P<0.01$ compared to TMX

activities at $8 \mathrm{~h}$ after the injection. Therefore, the dose of $90 \mathrm{mg} /$ $\mathrm{kg}$ was used in subsequent studies. Mice treated with TMX (90 mg/kg) exhibited apparent liver injury at 5, 8, and $20 \mathrm{~h}$ after the TMX injection, as indicated by increased serum ALT and AST activities (Fig. 1a, b). Pretreatment with osthole $(100 \mathrm{mg} / \mathrm{kg})$ significantly attenuated the increased ALT and AST activities. However, when osthole was administered simultaneously with or after the TMX injection, no significant protective effects were observed (data not shown). Osthole prevented TMX-induced hepatotoxicity in a dose-dependent manner (Fig. 1c, d). According to the histopathological analysis, the plates of hepatocytes became blurred in certain sections of the tissue $8 \mathrm{~h}$ after the TMX treatment. Meanwhile, hepatic cells in certain areas swelled into spherical shapes and fatty metamorphosis was observed. Pretreatment with osthole significantly alleviated the morphological changes in the liver induced by TMX (Fig. 1e). These results indicated a significant beneficial effect of osthole on TMXinduced hepatotoxicity.

Osthole alleviated TMX-induced oxidative stress

We detected the status of oxidative stress in all groups. Serum levels of $\mathrm{H}_{2} \mathrm{O}_{2}$ and MDA were significantly reduced by osthole compared with TMX alone (Fig. 2a, b). TMX dramatically depleted GSH and markedly increased the GSSG-to-GSH ratio in serum, 

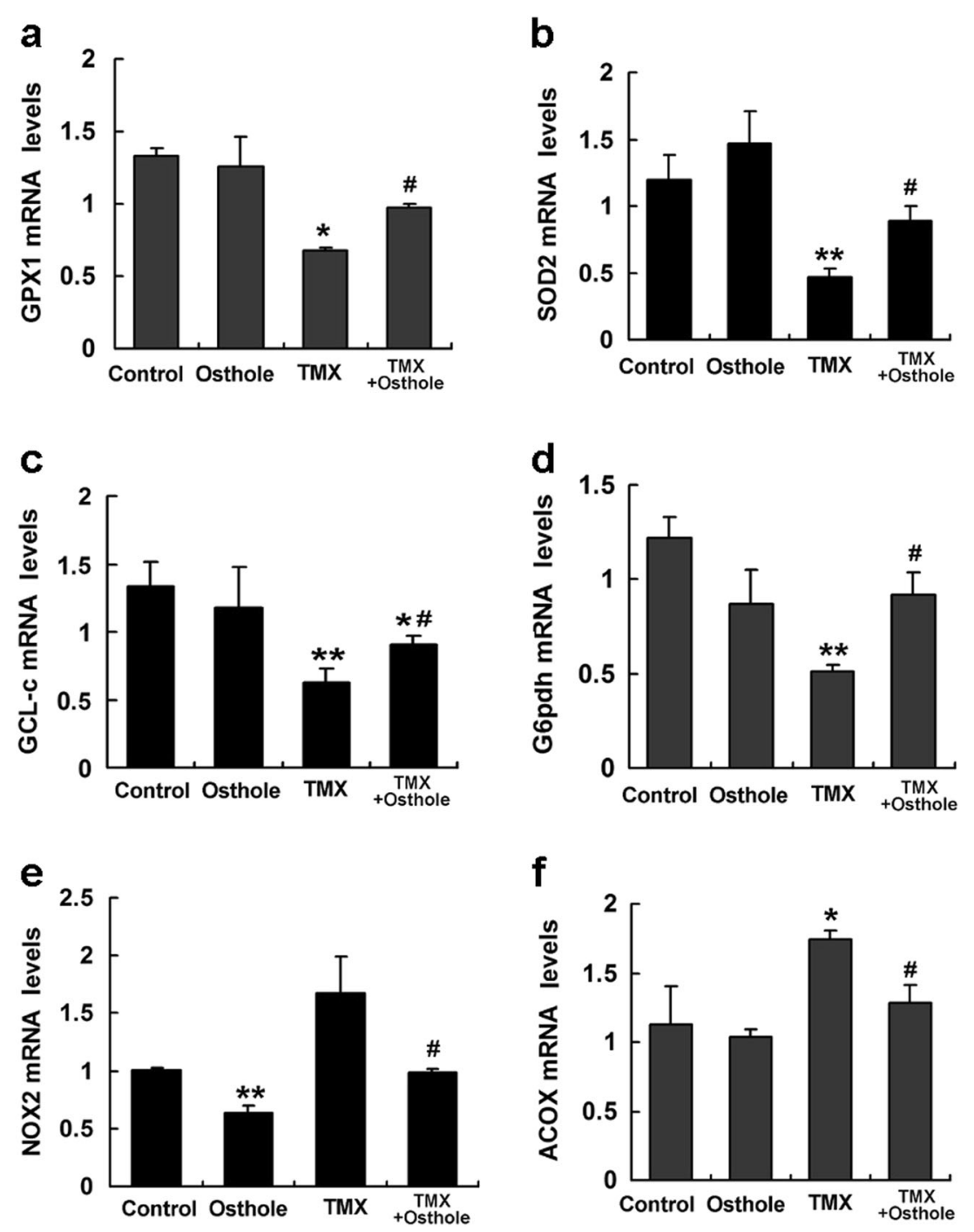

Fig. 3 Osthole significantly increased the expression of antioxidant genes (GPX1, SOD2, GCL-C, and G6pdh), but suppressed the expression of pro-oxidant genes (NOX2 and ACOX). Mice were intraperitoneally injected with osthole (100 mg/kg). After $24 \mathrm{~h}$, TMX $(90 \mathrm{mg} / \mathrm{kg})$ was administered to mice. Mice were sacrificed $8 \mathrm{~h}$ after the TMX injection, and the mRNA levels in the liver were quantified using real-time RT-PCR. Data are presented as the mean $\pm \mathrm{SEM}, n=4-5$ mice per group. ${ }^{*} P<0.05,{ }^{* *} P<0.01$ compared to the control, $\# P<0.05$ compared to TMX

while osthole significantly improved both parameters (Fig. 2c, d). Similar effects of osthole were also observed on hepatic $\mathrm{H}_{2} \mathrm{O}_{2}$ and GSH levels (Fig. 2e, f). Additionally, TMX induced an increase in total ROS levels (superoxide levels were measured by DHE staining) in the mouse liver, whereas this effect was significantly alleviated by osthole (Fig. 2g). The hepatic levels of LPO, which were enhanced by TMX, were also dramatically suppressed by osthole (Fig. 2h).

As excessive ROS accumulate as a result of an imbalance between the ROS generating and scavenging systems, we next compared the mRNA levels of key genes involved in both processes using real-time PCR. Osthole significantly increased the expression of antioxidant genes glutathione peroxidase-1 (GPX1), superoxide dismutase-2 (SOD2), y-glutamylcysteine ligase catalytic subunit (GCL-c), and glucose-6-phosphate dehydrogenase (G6pdh) (Fig. 3a-d), but suppressed the expression of prooxidant genes NADPH oxidase-2 (NOX2) and acyl-coenzyme A oxidase (ACOX) (Fig. 3e, f). Thus, osthole inhibited TMX-induced oxidative stress by reducing the formation and promoting the clearance of ROS.
Osthole reduced the TMX-induced inflammatory response TMX-induced liver injury is associated with sterile inflammation. We measured the hepatic levels of TNFa, IL-1 $\beta, I L-6$, and MCP-1 in mice $8 \mathrm{~h}$ after the TMX injection using real-time PCR to assess the effect of osthole on inflammatory cytokine production. Osthole significantly reduced the mRNA levels of these cytokines compared with TMX alone (Fig. 4a-d). Hepatic levels of the IL-1 $\beta$ and IL- 6 proteins exhibited similar alterations, as determined by ELISA (Fig. 4e, f). These findings were consistent with the known anti-inflammatory activity of this compound.

Osthole altered the activity of drug-metabolizing enzymes TMX activates enzymes responsible for its own activation, or conversely, suppresses the activity of enzymes responsible for its detoxification [8]. TMX is predominantly transformed into several metabolites by cytochrome P450-mediated pathways after oral administration [7]. Phase II enzymes in the liver, such as UGTs or SULTs, are known to be involved in the elimination and detoxification of TMX $[23,24]$. We first measured the expression 

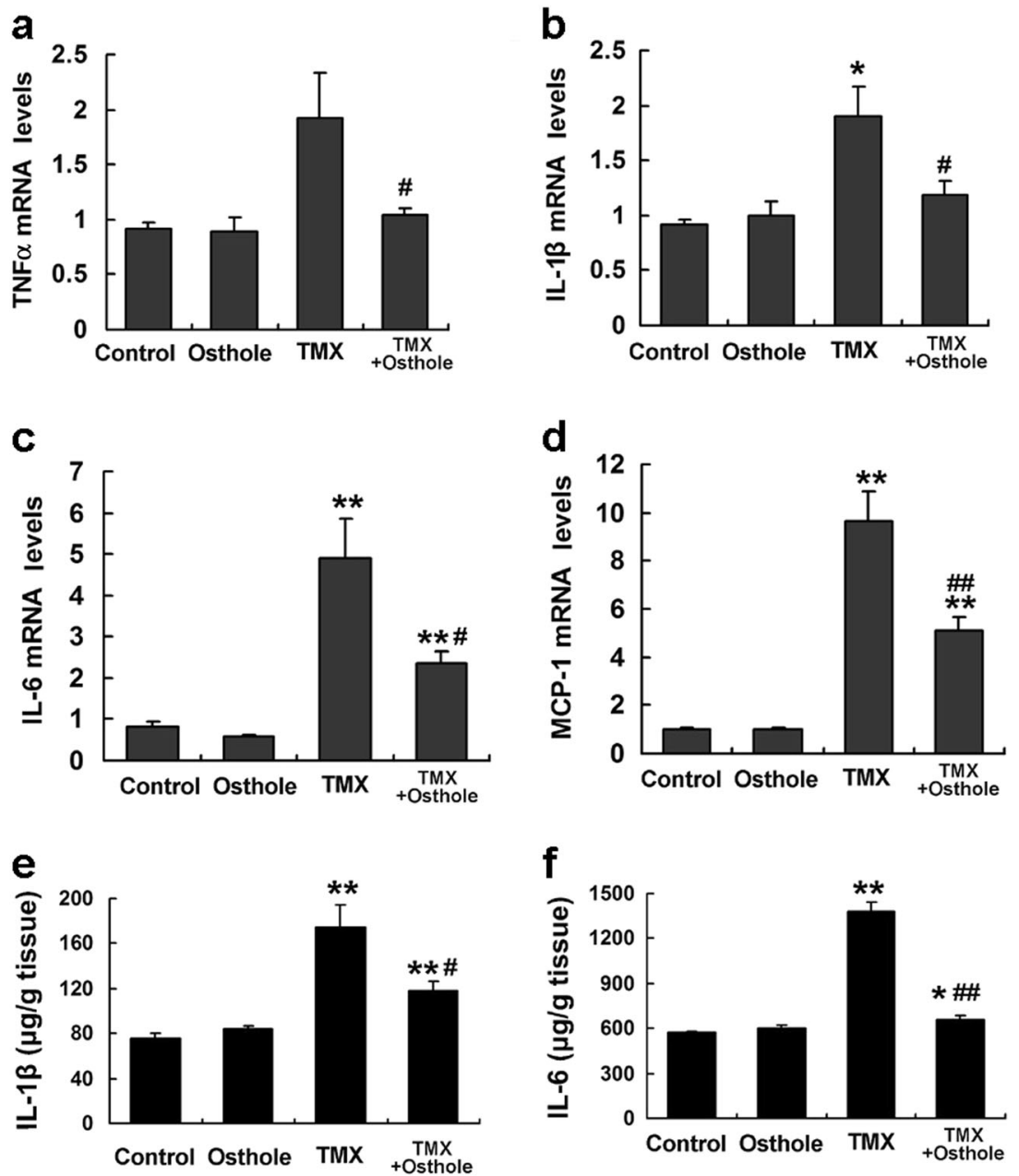

Fig. 4 Osthole reduced the TMX-induced inflammatory response. Mice were intraperitoneally injected with osthole (100 mg/kg). After $24 \mathrm{~h}$, TMX $(90 \mathrm{mg} / \mathrm{kg})$ was administered to mice. Mice were sacrificed $8 \mathrm{~h}$ after the TMX injections. a-d The levels of inflammation-related mRNAs in the liver were quantified using real-time RT-PCR. e, $\mathbf{f}$ Hepatic IL-1 $\beta$ and IL- 6 levels were detected using ELISAs. Data are presented as the mean \pm SEM, $n=4-5$ mice per group. ${ }^{*} P<0.05,{ }^{* *} P<0.01$ compared to the control, ${ }^{\#} P<0.05,{ }^{\# \#} P<0.01$ compared to TMX

of phase enzymes using real-time PCR to investigate the effect of osthole on TMX metabolism. Osthole significantly inhibited the TMX-induced increase in the expression of the CYP2D6, CYP2E1, CYP3A11, and CYP4A10 genes (Fig. 5a-d). Among phase II enzymes, the expression of UGT1A1, UGT1A6, UGT2B1, SULT2A1, and GSTM was increased in osthole-pretreated mice compared with mice treated with TMX alone (Fig. $5 \mathrm{e}-\mathrm{i}$ ). Similar alterations were also detected in levels of the UGT1A1 and SULT2A1 proteins by western blotting (Supplementary Figure S2). Based on these findings, osthole reduced TMX hepatotoxicity by inhibiting its metabolic activation and promoting its clearance.

The protective effects of osthole on TMX-induced hepatotoxicity were independent of the CAMP/PKA and cGMP/PKG pathways Based on accumulating evidence, osthole induces nonspecific increases in intracellular and tissue CAMP and CGMP levels by inhibiting phosphodiesterases (PDEs) $[25,26]$. We therefore determined CAMP and cGMP levels in the mouse liver. Prominent reductions in CAMP and CGMP levels were observed $8 \mathrm{~h}$ after the TMX treatment. Osthole significantly restored hepatic CAMP and cGMP levels compared with TMX alone (Fig. 6a, b). CAMP and CGMP mainly work by activating protein kinase $A$ (PKA) and protein kinase $\mathrm{G}(\mathrm{PKG})$, respectively. Therefore, the PKA-selective inhibitor $\mathrm{H} 89$ or PKG-selective inhibitor KT5823 was used to determine whether the hepatoprotective effect of osthole was mediated by the CAMP/PKA or CGMP/PKG pathways. The H89 or KT5823 pretreatment failed to abolish osthole-induced reductions in ALT and AST activities (Fig. 6c-f). Meanwhile, the effects of osthole on the TMX-induced alterations in the expression of genes involved in oxidative stress, inflammation, and metabolism were not reversed by $\mathrm{H} 89$ (Fig. $6 \mathrm{~g}-\mathrm{i}$ ). Similar results were obtained with KT5823 (data not shown). Thus, the protective effects of osthole on TMX-induced injury were independent of the CAMP/PKA and cGMP/PKG pathways.

Osthole attenuated TMX-induced liver injury by decreasing p38 phosphorylation

We examined the levels of phosphorylated MAPK in the mouse liver. Compared with the control, prominent phosphorylation of p38 was observed in mice $8 \mathrm{~h}$ after the TMX treatment. Osthole significantly inhibited TMX-induced p38 activation (Fig. 7a, b). No detectable changes were observed in the levels of phosphorylated Erk and JNK (Fig. 7a, c, d). Mice were injected with the p38 inhibitor SB203580 $1 \mathrm{~h}$ before the TMX injection to explore the role of p38 inhibition in the protective effects of osthole on TMX-induced hepatotoxicity. SB203580 significantly attenuated the TMX-induced increase in ALT and AST activities (Fig. 7e, f). Meanwhile, 

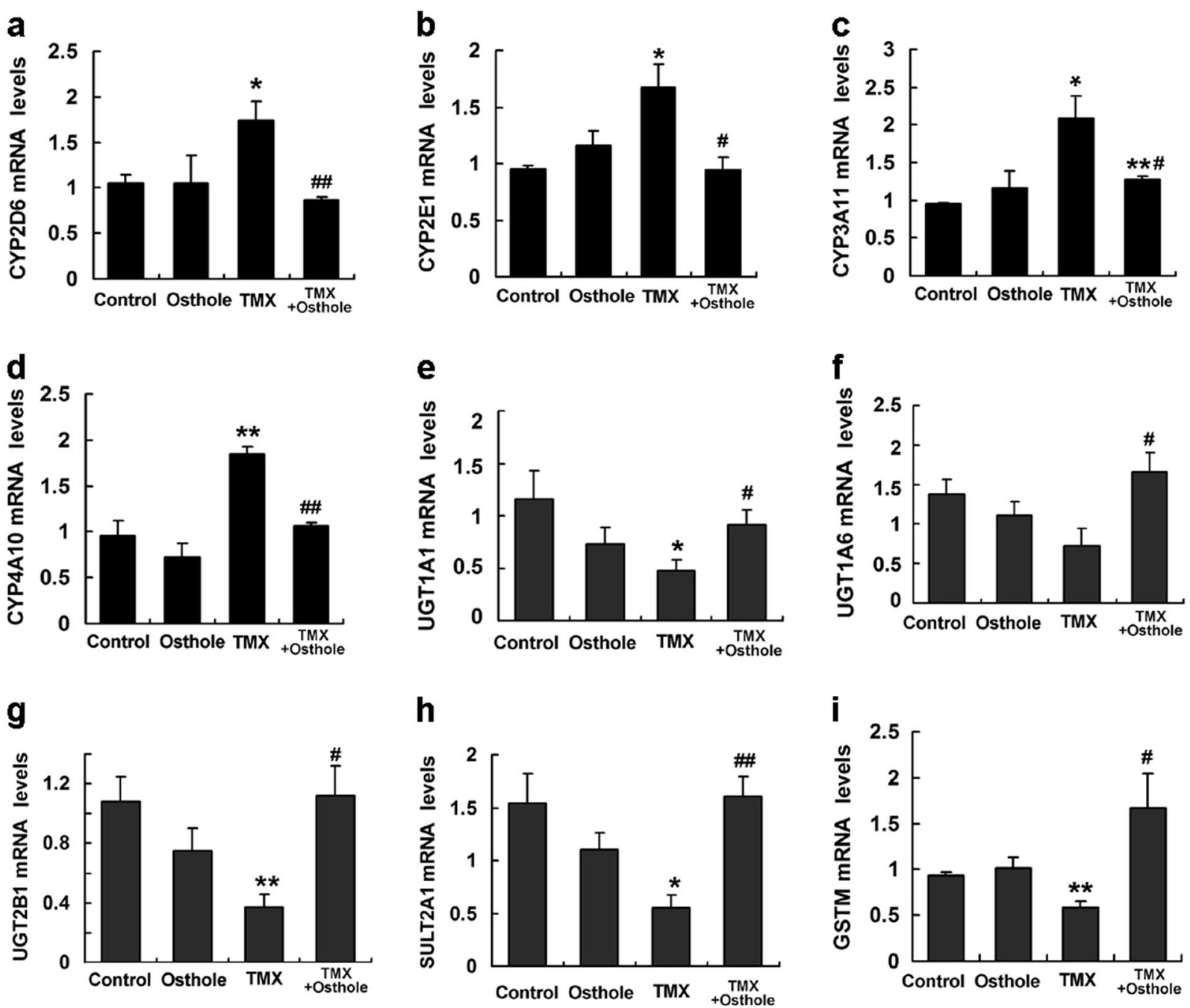

Fig. 5 Osthole altered the activities of metabolizing enzymes. a-i Mice were intraperitoneally injected with osthole (100 mg/kg). After $24 \mathrm{~h}$, TMX $(90 \mathrm{mg} / \mathrm{kg})$ was administered to mice. Mice were sacrificed $8 \mathrm{~h}$ after the TMX injection, and the mRNA levels of genes involved in the metabolism of TMX in the liver were quantified using real-time RT-PCR. Data are presented as the mean \pm SEM, $n=4-5$ mice per group. ${ }^{*} P<0.05,{ }^{* *} P<0.01$ compared to the control, ${ }^{\#} P<0.05$, ${ }^{\#} P<0.01$ compared to TMX

SB203580 significantly alleviated TMX-induced oxidative stress, as manifested by reduced hepatic levels of $\mathrm{H}_{2} \mathrm{O}_{2}$ (Fig. $7 \mathrm{~g}$ ) and MDA (Fig. 7h), and the recovery of GSH levels (Fig. 7i) compared with TMX alone. Consistent with these findings, SB203580 exerted similar effects on the serum levels of $\mathrm{H}_{2} \mathrm{O}_{2}$, GSH, and GSSG-to-GSH ratio (Supplementary Figure S3). Realtime PCR revealed that SB203580 altered the TMX-induced changes in the expression of genes involved in oxidative stress, inflammation, and metabolism to a similar extent as osthole (Fig. 8). Based on these results, the protective effects of osthole on TMX-induced hepatotoxicity are mediated by a decrease in P38 phosphorylation.

Osthole protected against TMX-induced hepatotoxicity through its antioxidant effects

Mice that had been pretreated with osthole were intraperitoneally injected with L-buthionine sulfoximine (BSO), an inhibitor of GSH synthesis, $1 \mathrm{~h}$ prior to the administration of TMX to determine whether the antioxidant activity of osthole was responsible for its protective effects on TMX-induced liver injury. We found that BSO partially reversed the osthole-induced reduction in ALT and AST activities (Fig. 9a, b). Consistent with these findings, NAC, a GSH precursor, significantly attenuated TMX-induced increases in ALT and AST activities (Fig. 9c, d). Real-time PCR showed that the effects of osthole on the expression of genes involved in oxidative stress, inflammation, and metabolism were reversed by the BSO treatment (Fig. 9e-g). These results confirmed that the hepatoprotective effects of osthole were partially mediated by its antioxidant activity. Notably, the BSO treatment did not affect osthole-induced suppression of p38 activation (Fig. 9h, i). Meanwhile, NAC did no exert a detectable effect on TMX-induced phosphorylation of p38 (Fig. 9j, k). Combined with the findings that the p38 inhibitor SB203580 significantly alleviated TMXinduced oxidative stress, we conclude that p38 activation mediates oxidative stress during TMX-induced hepatotoxicity. The antioxidant activity of osthole is at least in partially mediated by its inhibitory effect on p38 activation.

\section{DISCUSSION}

TMX is viewed as a highly effective anticancer endocrinotherapy; however, its various side effects must be considered [2]. Among these side effects, hepatic injury or even hepatocarcinoma (which has only been reported in rats) [4] are some of the most severe 
a
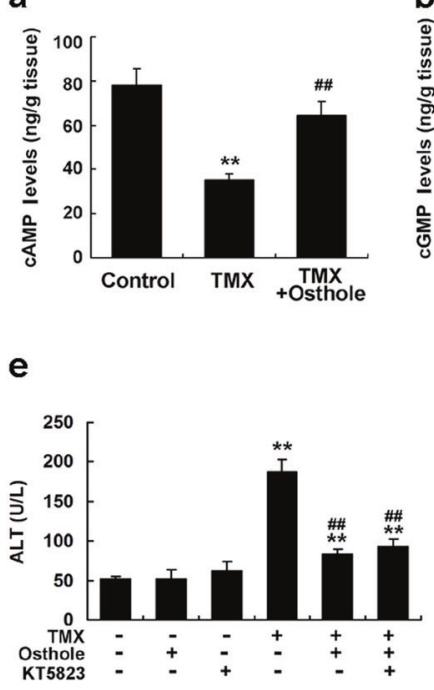

h

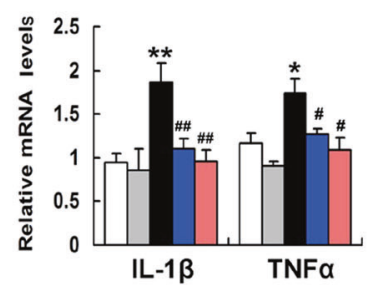

b

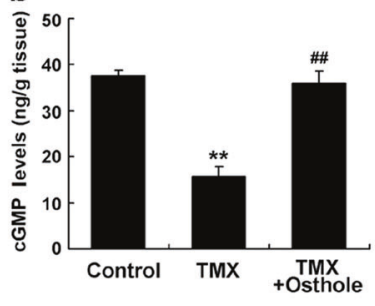

f

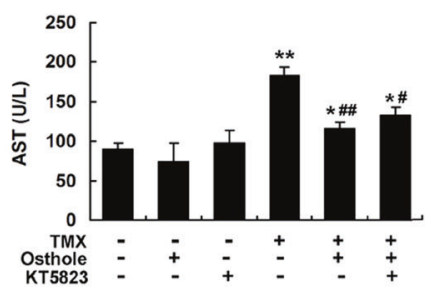

g

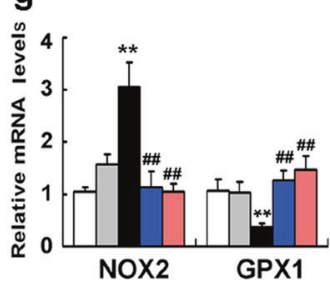

i

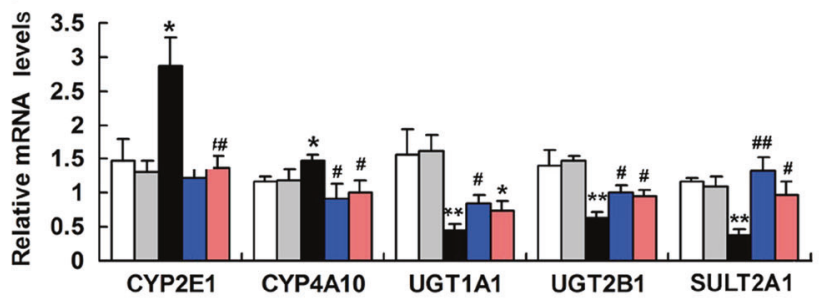

Fig. 6 The protective effects of osthole on TMX-induced hepatotoxicity were independent of the cAMP/PKA and cGMP/PKG pathways. a, b Mice were intraperitoneally injected with osthole $(100 \mathrm{mg} / \mathrm{kg})$. After $24 \mathrm{~h}$, TMX $(90 \mathrm{mg} / \mathrm{kg})$ was administered to mice. Mice were sacrificed $8 \mathrm{~h}$ after the TMX injection. Hepatic CAMP and cGMP levels were determined. $\mathbf{c}, \mathbf{d}$ H89 $(10 \mathrm{mg} / \mathrm{kg})$ was intraperitoneally injected into mice $1 \mathrm{~h}$ prior to the TMX injection. Serum ALT and AST activities were measured $8 \mathrm{~h}$ after the TMX injection. e, f KT5823 (25 mg/kg) was intraperitoneally injected into mice $1 \mathrm{~h}$ prior to the TMX injection. Serum ALT and AST activities were measured $8 \mathrm{~h}$ after the TMX injection. g-i Hepatic mRNA levels of genes involved in oxidative stress, inflammation, and metabolism were quantified using real-time RT-PCR at $8 \mathrm{~h}$ after the TMX injection. Data are presented as the mean \pm SEM, $n=4-6$ mice per group. ${ }^{*} P<0.05,{ }^{*} P<0.01$ compared to the control, ${ }^{\#} P<0.05,{ }^{\#} P<0.01$ compared to TMX

side effects, which hinders its long-term use. In the present study, a pretreatment with osthole significantly prevented the TMXinduced increases in serum ALT and AST activities. Osthole inhibited TMX-induced hepatic GSH depletion and ROS accumulation. Consistent with these findings, osthole significantly increased the expression of antioxidant genes, but suppressed the expression of pro-oxidant genes. Osthole reduced inflammatory cytokine production, suppressed the metabolic activation of TMX, and promoted TMX clearance. Additionally, osthole ameliorated the histopathological changes caused by TMX. Therefore, osthole is an effective treatment that protects against TMX-induced acute liver injury.

Although TMX-induced hepatotoxicity has been attributed to oxidative stress caused by its direct actions or generated during its metabolism in the liver [3], the underlying signaling pathways remain unknown. In the present study, we showed prominent activation of p38 MAPK by TMX. Inhibition of p38 with SB203580 significantly attenuated TMX-induced increases in ALT and AST activities, reduced oxidative stress, and reversed the TMXinduce alterations in gene expressions. In contrast, NAC, a GSH precursor that significantly attenuates TMX-induced liver damage, did not exert a detectable effect on the levels of phosphorylated p38. Based on these findings indicate, activated p38 mediates TMX-induced oxidative stress and hepatotoxicity. Moreover in TMX-induced hepatotoxicity, increased oxidative stress is not the cause of p38 activation, but is a consequence. Currently, the mechanism by which TMX activates p38 remains unknown.
Studies aiming to identify the factors responsible for activating p38 in TMX-induced hepatotoxicity will be potentially important for the treatment of this disease.

In the present study, osthole significantly inhibited the TMXinduced activation of p38. As shown in our previous report, osthole attenuates p38 phosphorylation in mouse peritoneal macrophages and Raw264.7 cells [27]. The effects of osthole on MAPK activation were also investigated in several other studies. In prostate cancer cells and HepG2 cells, osthole attenuates metastasis or inflammatory responses by inhibiting phosphorylation of Erk, JNK, and p38 [28, 29]. In contrast, osthole alleviates hepatic injury after trauma-induced hemorrhaging by increasing p38 activation [20]. These contradictory findings suggest that the effects of osthole on MAPK activation are complicated and are closely related to the cellular context and the type of stimulus. The phosphorylation levels of upstream kinases should be investigated to understand the mechanism underlying the suppressive effects of osthole on TMX-induced p38 activation.

In TMX-induced hepatotoxicity, liver injury is associated with sterile inflammatory responses, as evidenced by increased expression of inflammatory cytokines. Osthole exerts its antiinflammatory function by increasing intracellular and tissue cAMP and/or cGMP levels via the inhibition of PDEs $[25,26]$. In the current study, osthole significantly restored hepatic CAMP and cGMP levels compared with TMX alone. However, inhibition of PKA or PKG did not alter the protective effects of osthole on TMX- 
a

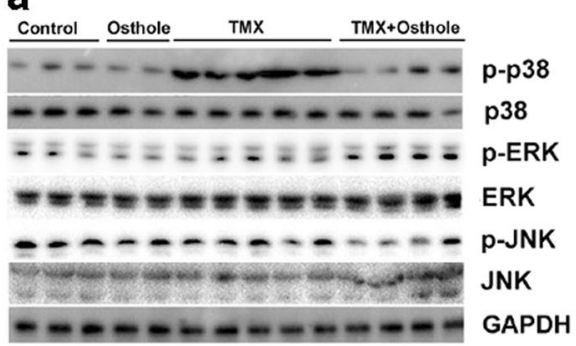

d

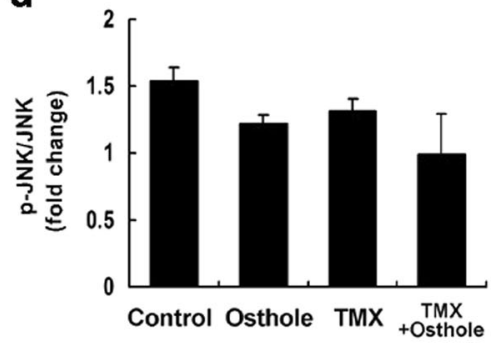

g

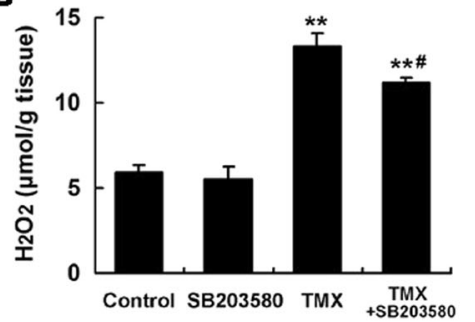

b

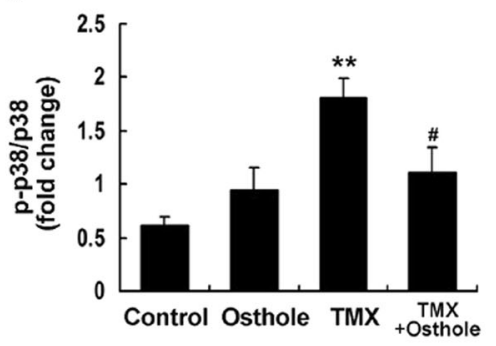

e

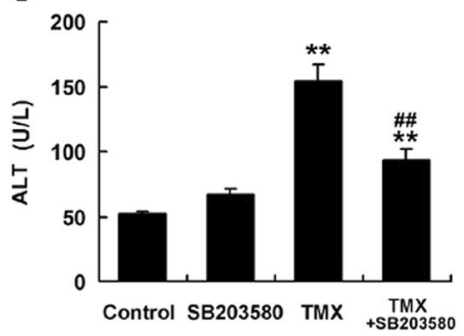

h

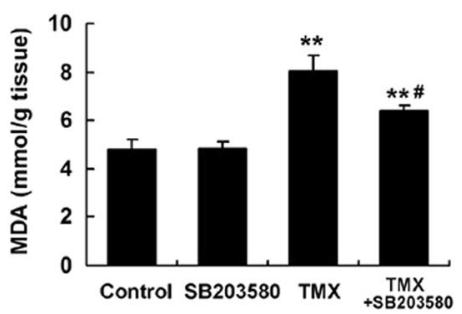

C

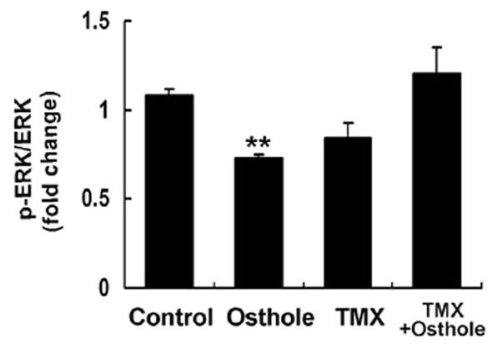

f

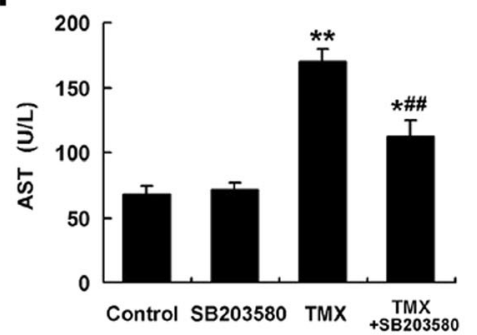

i

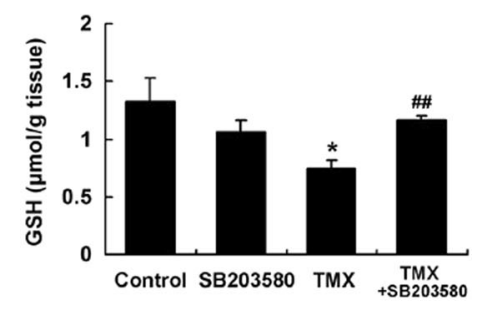

Fig. 7 Osthole attenuated TMX-induced liver injury by inhibiting P38 phosphorylation. a Mice were intraperitoneally injected with osthole (100 mg/kg). After $24 \mathrm{~h}$, TMX $(90 \mathrm{mg} / \mathrm{kg})$ was administered to mice. Mice were sacrificed $8 \mathrm{~h}$ after the TMX injections. Western blot analyses of the liver homogenates were performed. b-d Quantitation of the data shown in a. e-i Mice were injected with the p38 inhibitor SB203580 ( $2 \mathrm{mg} / \mathrm{kg}) 1 \mathrm{~h}$ before the TMX injection. Serum ALT and AST activities were measured $8 \mathrm{~h}$ after the TMX injection (e, f). Hepatic $\mathrm{H}_{2} \mathrm{O}_{2}(\mathbf{g})$, MDA (h), and GSH (i) levels were measured. Data are reported as the mean $\pm \mathrm{SEM}, n=4-6$ mice per group. ${ }^{*} P<0.05$, ${ }^{* *} P<0.01$ compared to the control, ${ }^{\#} P<0.05$, ${ }^{\# \#} P<0.01$ compared to TMX

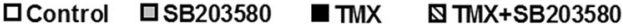
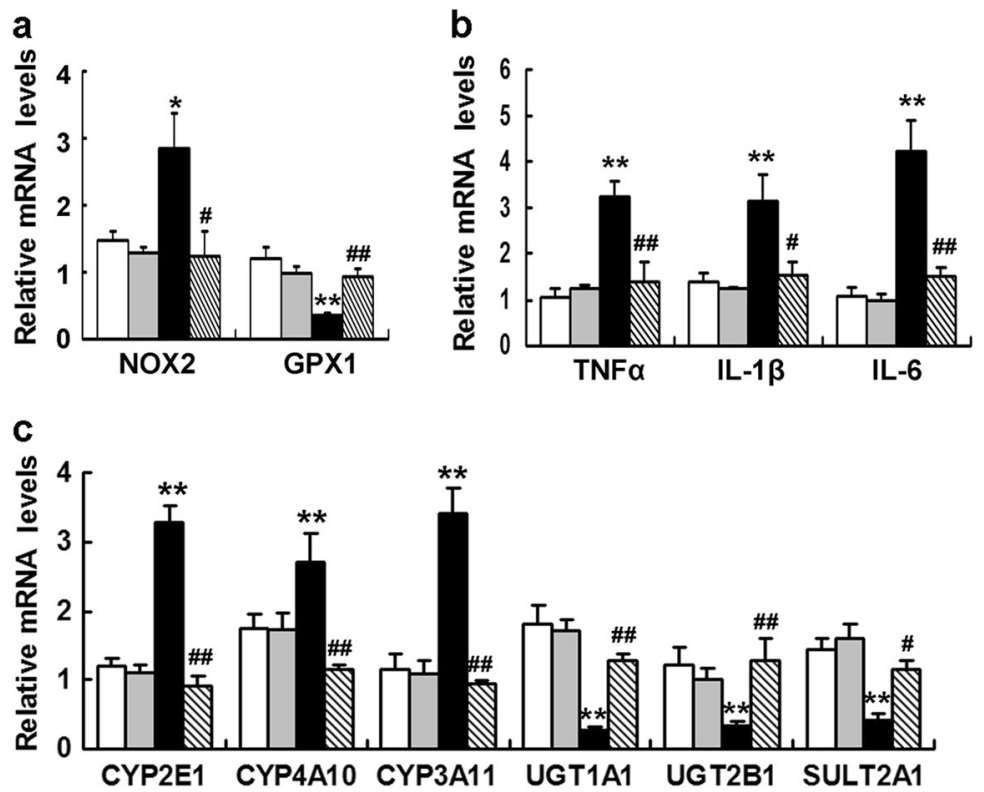

Fig. 8 Effects of SB203580 on TMX-induced changes in hepatic gene expression. Mice were injected with the p38 inhibitor SB203580 (2 mg/kg) $1 \mathrm{~h} \mathrm{before} \mathrm{the}$ TMX injection. The mRNA levels of genes involved in oxidative stress (a), inflammation (b), and metabolism (c) were quantified using real-time RT-PCR $8 \mathrm{~h}$ after the TMX injection. Data are reported as the mean \pm SEM $n=4-6$ mice per group. ${ }^{*} P<0.05,{ }^{* *} P<0.01$ compared to the control, ${ }^{\#} P<0.05$, ${ }^{\#} P<0.01$ compared to TMX 

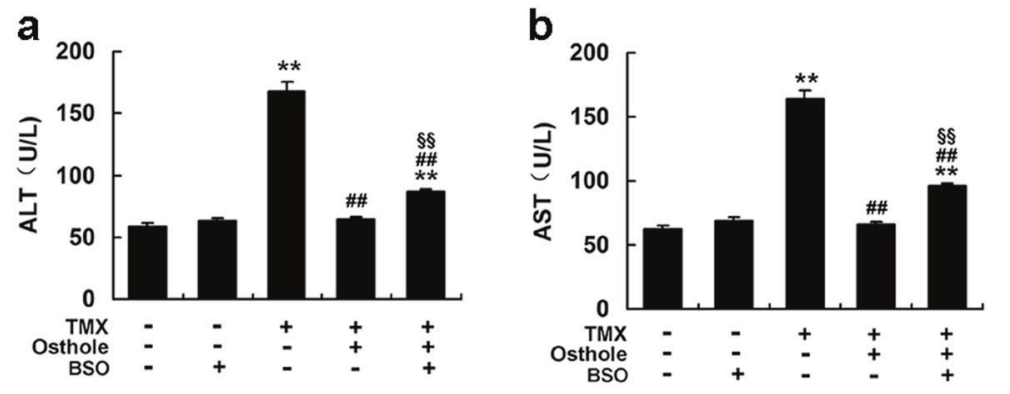

C
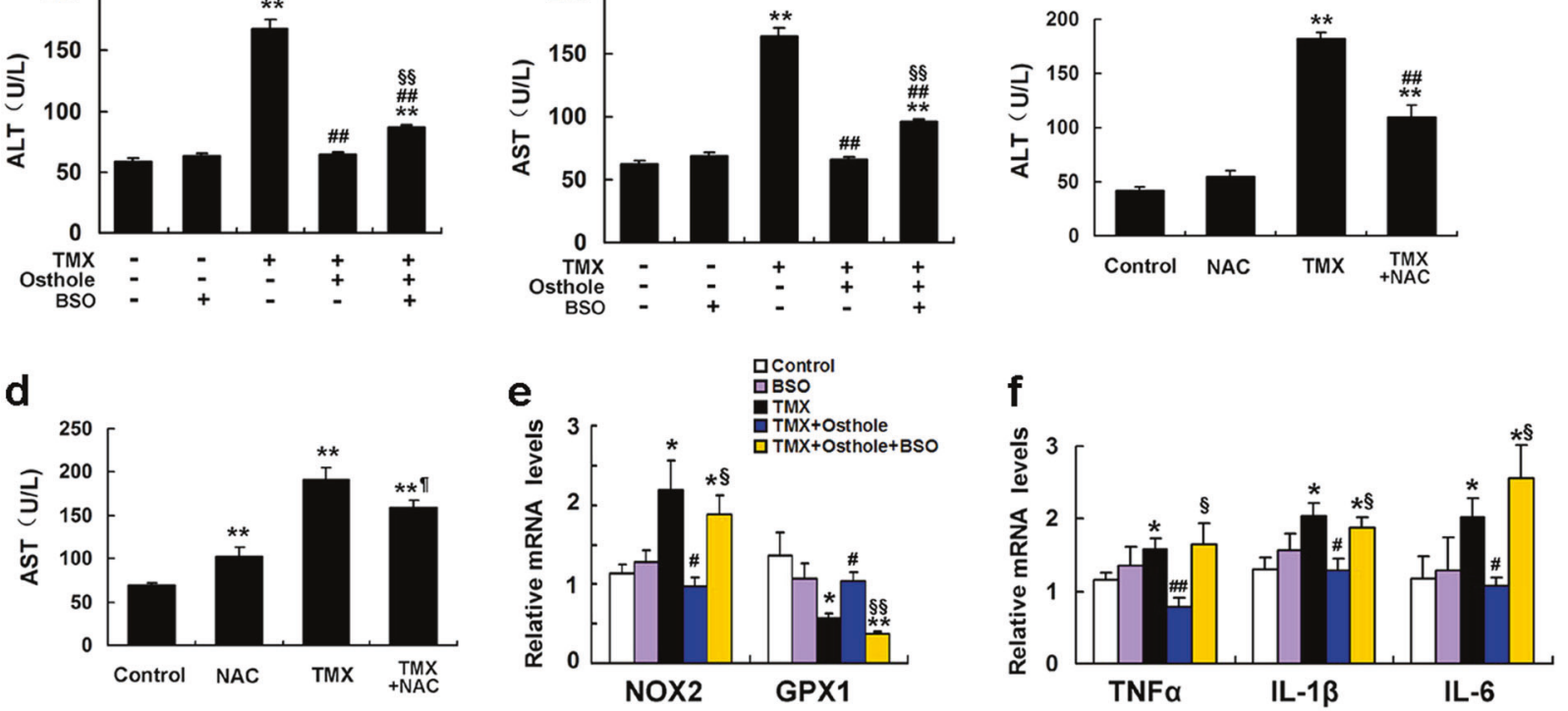

\section{g}

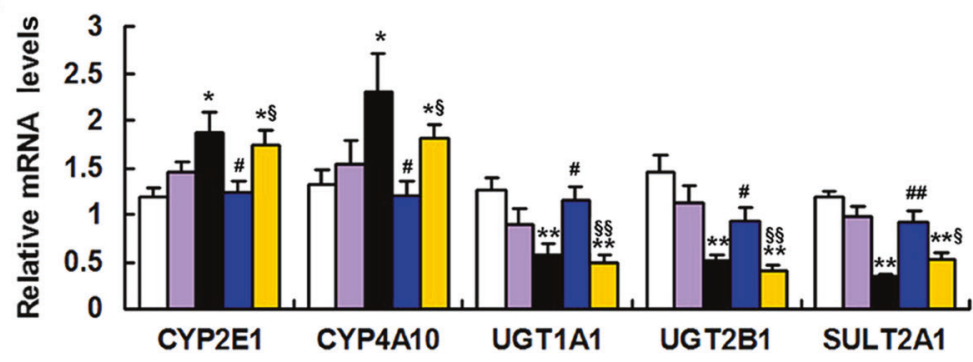

h

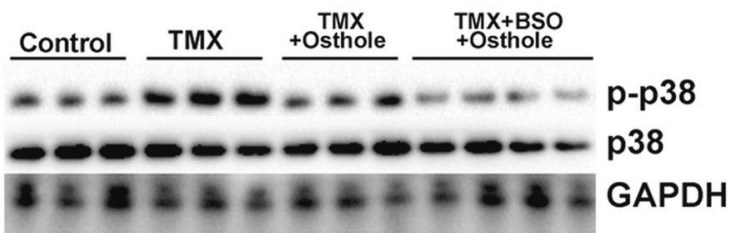

j

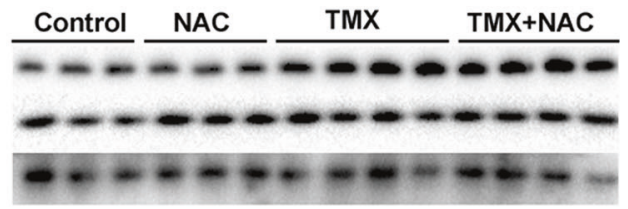

p-p38

p38

GAPDH i
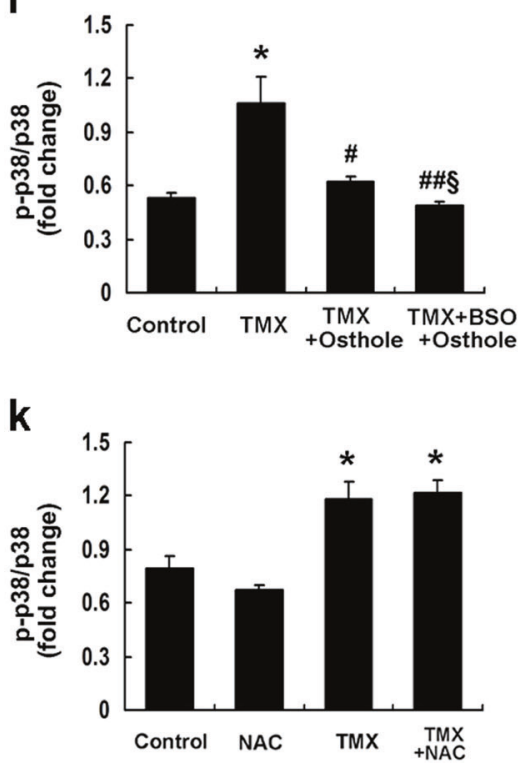

Fig. 9 The hepatoprotective effect of osthole was mediated by its antioxidant activity. $\mathbf{a}$, $\mathbf{b}$ Mice were intraperitoneally injected with osthole $(100 \mathrm{mg} / \mathrm{kg})$. After $24 \mathrm{~h}$, BSO $(1 \mathrm{~g} / \mathrm{kg})$ was intraperitoneally injected into mice $1 \mathrm{~h}$ prior to the TMX injection. Serum ALT and AST activities were measured $8 \mathrm{~h}$ after the TMX injection. c, d Mice were injected with NAC (150 mg/kg) $1 \mathrm{~h}$ before the TMX injection. Serum ALT and AST activities were measured $8 \mathrm{~h}$ after the TMX injection. e-g Mice were intraperitoneally injected with osthole $(100 \mathrm{mg} / \mathrm{kg})$. After $24 \mathrm{~h}, \mathrm{BSO}(1 \mathrm{~g} / \mathrm{kg})$ was intraperitoneally injected into $1 \mathrm{~h}$ prior to the TMX injection. Hepatic mRNA levels of genes involved in oxidative stress, inflammation, and metabolism were quantified using real-time RT-PCR $8 \mathrm{~h}$ after the TMX injection. $\mathbf{h}$-k Livers were collected from the mice treated as described above. Western blot analysis and quantification were performed. Data are presented as the mean \pm SEM, $n=4-6$ mice per group. ${ }^{*} P<0.05$, ${ }^{* *} P<0.01$ compared to the control, ${ }^{\#} P<0.05$, ${ }^{\#} P<0.01$ compared to TMX, ${ }^{\S \S} P<0.01$ compared to TMX plus osthole, ${ }^{\S} P<0.05$ compared to TMX plus osthole 


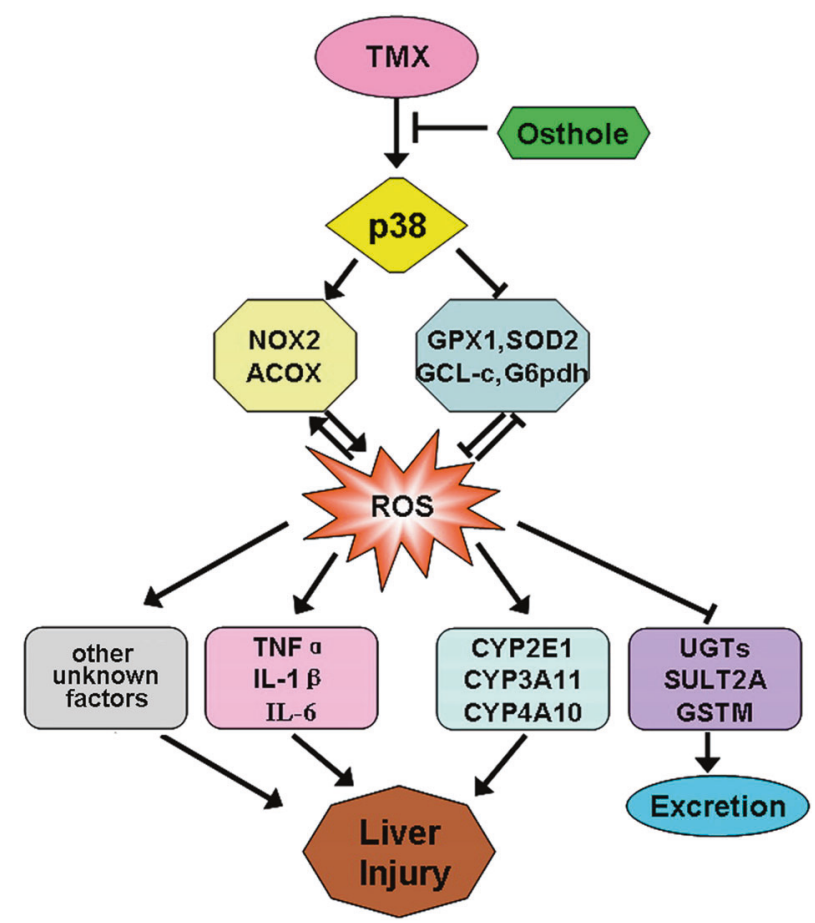

Fig. 10 Schematic illustration of the mechanism by which osthole protects against TMX-induced hepatotoxicity. By activating p38, TMX increases the expression of pro-oxidant genes and reduces the expression of antioxidant genes, leading to ROS accumulation. Oxidative stress increases inflammatory cytokine production, activates enzymes responsible for TMX activation, and suppresses enzymes responsible for its detoxification, all of which lead to liver injury. An osthole pretreatment suppresses TMX-induced p38 activation and inhibits ROS accumulation, thereby reducing TMXinduced liver injury

induced hepatotoxicity. Meanwhile, PKA inhibition did not alter the suppressive effect of osthole on p38 phosphorylation (Supplementary Figure S4). Therefore, the protective effects of osthole on TMX-induced hepatotoxicity are not mediated by its anti-inflammatory activity. Additionally, our findings also provide evidence refuting a role for inflammation in TMX-induced injury, although we were not able to exclude the possibility that some inflammatory mediators or intracellular signaling pathways may have directly affected the injury process. In the present study, osthole reduced the TMX-induced inflammatory response. This change may be a direct effect of osthole since it significantly restored hepatic CAMP and CGMP levels compared with TMX alone. Meanwhile, because elevated oxidative stress may lead to inflammation, osthole may also suppress inflammation by reducing $T M X$-induced ROS production.

As shown in our previous report using mouse peritoneal macrophages, the inhibitory effects of osthole on LPS-stimulated expression of cytokines such as IL-1 $\beta$, IL-6, COX2, and MCP-1 were completely reversed by PKA inhibitors [14]. In contrast, in our current study, inhibition of p38, but not PKA or PKG, mediated the protective effects of osthole on TMX-induced hepatotoxicity. Therefore, the anti-inflammatory and antioxidant effects of osthole are mediated by different pathways. PKA or PKG is involved in its anti-inflammatory function, while p38 is involved in its antioxidant effect.

Since metabolic transformation of TMX into electrophilic intermediates by cytochrome P450 in the liver results in the overproduction of ROS, the metabolism and elimination of TMX are partially responsible for the subsequent oxidative liver damage. Notably, the BSO treatment affected the expression of phase I and II enzymes. In fact, the cellular redox status has been shown to regulate the induction of UGTs [30] and CYPs [31]. Therefore, we speculate that the alterations in TMX-metabolizing enzymes induced by osthole were related to the antioxidant properties of this compound.

Osthole failed to attenuate TMX-induced death of isolated primary mouse hepatocytes (data not shown). Consistent with this finding, osthole did not exert beneficial effects on APAP-induced cell injury in vitro [21]. In contrast, osthole displays anti-inflammatory activities both in vivo and in vitro [27]. Currently, researchers have not determine why osthole only exerts its antioxidant effects in vivo. Further studies are needed to clarify this issue.

\section{CONCLUSIONS}

In this study, the protective effects of osthole on TMX-induced hepatotoxicity in mice were evaluated. By activating p38, TMX increases the expression of pro-oxidant genes and reduces the expression of antioxidant genes, leading to ROS accumulation. Oxidative stress increases the production of inflammatory cytokines, activates enzymes responsible for TMX activation, and suppresses enzymes responsible for its detoxification, all of which lead to liver injury. An osthole pretreatment suppresses TMXinduced p38 activation, inhibits ROS accumulation, and thereby reduces liver injury caused by TMX (Fig. 10). Osthole should be considered a potential natural resource to develop hepatoprotective agents targeting TMX-induced hepatotoxicity.

\section{ACKNOWLEDGEMENTS}

This work was supported by grants from the National Natural Science Foundation of China (No. 81270944 and No. 81070678) to Hao Li. Dr. Hao Li is an Associate Fellow at the Collaborative Innovation Center For Cardiovascular Disease Translational Medicine.

\section{AUTHOR CONTRIBUTIONS}

$W Z$ and $H L$ designed the study. $W Z, X Z$, and $Y C$ performed the experiments. $X Z$ and WS assisted in caring for the animals. WZ and WS performed the data analyses. $\mathrm{HL}$ and WZ wrote the manuscript.

\section{ADDITIONAL INFORMATION}

The online version of this article (https://doi.org/10.1038/s41401-018-0171-y) contains supplementary material, which is available to authorized users.

Competing interests: The authors declare no competing interests.

\section{REFERENCES}

1. Jordan VC. Tamoxifen: a most unlikely pioneering medicine. Nat Rev Drug Discov. 2003;2:205-13

2. Yang G, Nowsheen S, Aziz K, Georgakilas AG. Toxicity and adverse effects of Tamoxifen and other anti-estrogen drugs. Pharmacol Ther. 2013;139:392-404.

3. Dragan YP, Fahey S, Nuwaysir E, Sattler C, Babcock K, Vaughan J, et al. The effect of tamoxifen and two of its non-isomerizable fixed-ring analogs on multistage rat hepatocarcinogenesis. Carcinogenesis. 1996;17:585-94.

4. Karki A, Mantyla E, Hirsimaki Y, Karlsson S, Toikkanen S, Hirsimaki P. Comparison of the effects of tamoxifen and toremifene on rat hepatocarcinogenesis. Arch Toxicol. 2000;74:249-56.

5. Farrell GC. Drugs and steatohepatitis. Semin Liver Dis. 2002;22:185-94.

6. Ribeiro MP, Santos $A E$, Custódio JB. Mitochondria: the gateway for tamoxifeninduced liver injury. Toxicology. 2014;323:10-8.

7. Desai PB, Nallani SC, Sane RS, Moore LB, Goodwin BJ, Buckley DJ, et al. Induction of cytochrome P450 3A4 in primary human hepatocytes and activation of the human pregnane $\mathrm{X}$ receptor by tamoxifen and 4-hydroxytamoxifen. Drug Metab Dispos: Biol fate Chem. 2002;30:608-12.

8. Nuwaysir EF, Daggett DA, Jordan VC, Pitot HC. Phase II enzyme expression in rat liver in response to the antiestrogen tamoxifen. Cancer Res. 1996;56:3704-10.

9. Wang R, Kong J, Wang D, Lien LL, Lien EJ. A survey of Chinese herbal ingredients with liver protection activities. Chin Med. 2007:2:5. 
10. You L, Feng S, An R, Wang X. Osthole: a promising lead compound for drug discovery from a traditional Chinese medicine (TCM). Nat Product Commun. 2009;4:297-302.

11. Hoult JR, Paya M. Pharmacological and biochemical actions of simple coumarins: natural products with therapeutic potential. Gen Pharmacol. 1996;27:713-22.

12. Huang RL, Chen CC, Huang YL, Hsieh DJ, Hu CP, Chen CF, et al. Osthole increases glycosylation of hepatitis $B$ surface antigen and suppresses the secretion of hepatitis B virus in vitro. Hepatology. 1996;24:508-15.

13. Okamoto T, Yoshida S, Kobayashi T, Okabe S. Inhibition of concanavalin Ainduced mice hepatitis by coumarin derivatives. Jpn J Pharmacol. 2001;85:95-7.

14. Okamoto T, Kawasaki T, Hino O. Osthole prevents anti-Fas antibody-induced hepatitis in mice by affecting the caspase-3-mediated apoptotic pathway. Biochem Pharmacol. 2003;65:677-81.

15. Qi Z, Xue J, Zhang Y, Wang H, Xie M. Osthole ameliorates insulin resistance by increment of adiponectin release in high-fat and high-sucrose-induced fatty liver rats. Planta Med. 2011;77:231-5.

16. Zhang J, Xue J, Wang $H$, Zhang $Y$, Xie M. Osthole improves alcohol-induced fatty liver in mice by reduction of hepatic oxidative stress. Phytother Res: PTR. 2011;25:638-43.

17. Liu YW, Chiu YT, Fu SL, Huang YT. Osthole ameliorates hepatic fibrosis and inhibits hepatic stellate cell activation. J Biomed Sci. 2015;22:63.

18. Zhang L, Jiang G, Yao F, Liang G, Wang F, Xu H, et al. Osthole promotes antitumor immune responses in tumor-bearing mice with hepatocellular carcinoma. Immunopharmacol Immunotoxicol. 2015;37:301-7.

19. Zhang L, Jiang G, Yao F, He Y, Liang G, Zhang Y, et al. Growth inhibition and apoptosis induced by osthole, a natural coumarin, in hepatocellular carcinoma. PLoS ONE. 2012;7:e37865.

20. Yu HP, Liu FC, Tsai YF, Hwang TL. Osthole attenuates hepatic injury in a rodent model of trauma-hemorrhage. PLoS ONE. 2013;8:e65916.

21. Cai Y, Sun W, Zhang XX, Lin YD, Chen H, Li H. Osthole prevents acetaminopheninduced liver injury in mice. Acta Pharmacol Sin. 2018;39:74-84.
22. James LP, McCullough SS, Knight TR, Jaeschke H, Hinson JA. Acetaminophen toxicity in mice lacking NADPH oxidase activity: role of peroxynitrite formation and mitochondrial oxidant stress. Free Radic Res. 2003;37:1289-97.

23. Yang G, Shu XO, Ruan ZX, Cai QY, Jin F, Gao YT, et al. Genetic polymorphisms in glutathione-S-transferase genes (GSTM1, GSTT1, GSTP1) and survival after chemotherapy for invasive breast carcinoma. Cancer. 2005;103:52-8.

24. Blevins-Primeau AS, Sun D, Chen G, Sharma AK, Gallagher CJ, Amin S, et al Functional significance of UDP-glucuronosyltransferase variants in the metabolism of active tamoxifen metabolites. Cancer Res. 2009;69:1892-900.

25. Tsai YF, Yu HP, Chung PJ, Leu YL, Kuo LM, Chen $C Y$, et al. Osthol attenuates neutrophilic oxidative stress and hemorrhagic shock-induced lung injury via inhibition of phosphodiesterase 4. Free Radic Biol \& Med 2015;89:387-400.

26. Teng CM, Ko FN, Wang JP, Lin CN, Wu TS, Chen CC, et al. Antihaemostatic and antithrombotic effect of some antiplatelet agents isolated from Chinese herbs. J Pharm Pharmacol. 1991;43:667-9.

27. Sun W, Cai $Y$, Zhang XX, Chen $\mathrm{H}$, Lin YD, Li H. Osthole pretreatment alleviates TNBS-induced colitis in mice via both CAMP/PKA-dependent and independent pathways. Acta Pharmacol Sin. 2017;38:1120-8.

28. Wen YC, Lee WJ, Tan P, Yang SF, Hsiao M, Lee LM, et al. By inhibiting snail signaling and miR-23a-3p, osthole suppresses the EMT-mediated metastatic ability in prostate cancer. Oncotarget. 2015;6:21120-36.

29. Wu SJ. Osthole Attenuates Inflammatory Responses and Regulates the Expression of Inflammatory Mediators in HepG2 Cells Grown in Differentiated Medium from 3T3-L1 Preadipocytes. J Med Food. 2015;18:972-9.

30. Nguyen T, Sherratt PJ, Pickett CB. Regulatory mechanisms controlling gene expression mediated by the antioxidant response element. Annu Rev Pharmacol Toxicol. 2003;43:233-60.

31. Albertolle ME, Peter Guengerich $F$. The relationships between cytochromes $P 450$ and $\mathrm{H}_{2} \mathrm{O}_{2}$ : production, reaction, and inhibition. J Inorg Biochem. 2018; $186: 228-34$. 